\title{
REFLETINDO SOBRE EDUCAÇÃO FÍSICA ESCOLAR COM NARRATIVAS
}

\author{
Alexandre Scherer \\ Centro Universitário Metodista, Porto Alegre, Rio Grande do Sul, Brasil \\ Denise Grosso da Fonseca \\ Universidade Federal do Rio Grande do Sul, Porto Alegre, Rio Grande do Sul, Brasil \\ Ronaldo Robinson Martinez \\ Centro Universitário Metodista, Porto Alegre, Rio Grande do Sul, Brasil
}

\begin{abstract}
Resumo
O presente artigo resultou da proposta de um grupo de estudos quanto à realização de um exercício com narrativas, que envolveu professores-pesquisadores do próprio grupo e seus interlocutores, professores de escolas; teve como objetivo compreender as implicações das pesquisas realizadas nas instituições de ensino para si mesmas. A metodologia utilizada foi a da narrativa oral e também escrita, envolvendo três professores - dois pesquisadores do grupo e um professor de Educação Física de uma escola estadual. O estudo evidenciou que a pesquisa desenvolvida promoveu mudanças na trajetória dos professores, na organização administrativa, na estrutura física e também no material da escola, bem como em aspectos didático-pedagógicos do trabalho docente.
\end{abstract}

Palavras-chave: Educação Física Escolar. Narrativas. Diálogo.

\section{Introdução}

O presente artigo resultou da proposta de um grupo de estudos de realização de um exercício com narrativas, que envolveu professores-pesquisadores do próprio grupo e seus interlocutores, professores de escolas. Este, teve como objetivo compreender as implicações das pesquisas realizadas nas instituições de ensino para si mesmas e sua prática pedagógica de Educação Física.

\footnotetext{
Trabalhar com narrativas na pesquisa e/ou no ensino é partir para a desconstrução/construção das próprias experiências, tanto do professor/pesquisador como dos sujeitos da pesquisa e/ou do ensino. Exige que a relação dialógica se instale criando uma cumplicidade de dupla descoberta. Ao mesmo tempo em que se descobre no outro, os fenômenos revelam-se a nós (CUNHA, 1998, p. 39).
}

Concordamos com a autora que trabalhar com narrativas é um caminho de mão dupla, que exige um exercício de diálogo baseado na reflexão sobre o vivido, de modo que tanto o professorpesquisador quanto os sujeitos da pesquisa sintam-se cúmplices na relação que se estabelece. É o 
que Isaía (2003) conceitua como 'narrativa compartilhada'. Para ela, se estabelece uma interrelação do participante com o pesquisador convertendo-se num processo de autorreflexão coletiva, que dificilmente seria possibilitado a partir de estratégias mais tradicionais de coleta de informações, como, por exemplo, questionário e entrevista.

Neste sentido, entendemos que uma narrativa não se caracteriza somente pela descrição de um determinado sujeito envolvido na pesquisa, mas, sim, pelas reflexões que surgem e que envolvem o narrador e o ouvinte.

\section{Metodologia}

No presente estudo nos propusemos a dialogar sobre a Educação Física em uma escola da rede pública estadual, localizada na cidade de Porto Alegre (RS), a partir dos relatos de um professor, que passará a ser identificado como Professor da Escola (PE) e de dois pesquisadores do grupo, que passarão a ser identificados, respectivamente, como Professor Pesquisador (PP) e Professora Mediadora (PM). O primeiro participou das pesquisas de Mestrado e de Doutorado do Professor Pesquisador e a Professora Mediadora se envolveu no estudo como interlocutora, pois também já tinha sido supervisora de estágio na escola.

Desde os primeiros contatos com o Professor da Escola, a intenção foi de estabelecer uma relação de parceria e de cumplicidade, como menciona Cunha (1998). Hogan (1988) apud Connelly \& Clandinin (1995, p. 19) reforça essa ideia ao destacar alguns elementos importantes para a realização de uma investigação narrativa: "a igualdade entre os participantes, a situação de atenção mútua e os sentimentos de conexão". A partir deste cenário, estabelecemos que o objeto de estudo fosse uma análise da Educação Física na referida escola, procurando compreender as implicações das pesquisas realizadas nas mudanças ocorridas naquela instituição de ensino.

Deste processo emergiram alguns questionamentos importantes que visavam discutir/refletir sobre: 'Quais as implicações das pesquisas realizadas para o desenvolvimento da Educação Física na escola?' 'Que mudanças ocorreram a partir das pesquisas realizadas?' 'Que aspectos relacionados à estrutura física interferiram/interferem nas aulas de Educação Física?' 'Que fatores didático-pedagógicos ajudaram/ajudam ou dificultaram/dificultam a prática dos professores de Educação Física na escola em questão?'

Tais questões apresentaram-se como pontos de partida para a realização da narrativa oral, servindo para orientar os olhares, e não pretendendo estabelecer uma contenção para as inúmeras possibilidades que emergiram ao longo do trabalho. Assim, a partir desses questionamentos, que orientaram o rumo desta investigação, as análises apontam para a discussão das seguintes categorias: 'trajetória do professor', 'questões administrativas e estrutura física', e 'aspectos didático-pedagógicos'.

\section{Resultados e Discussão}

As ideias construídas, as reflexões suscitadas, os diálogos produzidos nos envolveram e nos fisgaram numa malha em que os 'nós' fomos 'nós', enquanto sujeitos reflexivos e refletidos nas tramas da realidade desvelada, da qual emergiram as categorias já destacadas.

A influência das pesquisas nas trajetórias dos professores 
Refletir sobre esta categoria nos remete, inicialmente, aos modelos de pesquisa tradicionalmente experimentados no meio educacional brasileiro. Mesmo num viés qualitativo, nos últimos 25 anos, professores e escolas têm participado de estudos que os concebem como sujeitos passivos num processo dirigido por um pesquisador que obtém os seus dados e se afasta do campo estudado. Tais ações de pesquisa não garantem modificação no cotidiano da escola nem na formação continuada dos professores.

Este fato foi evidenciado quando dialogamos sobre a pesquisa de Mestrado conduzida pelo Professor Pesquisador, realizada entre 1998 e 2000, e que envolveu esta mesma escola, juntamente com outras cinco da Rede Estadual, e mais o Professor da Escola com 15 outros docentes de Educação Física:

PP - Como o exercício de pesquisa de Mestrado se limitava em verificar como era o ambiente da Educação Física escolar, não houve procedimento algum em alterar aquela sistemática naquele momento. A reflexão sobre a pesquisa me levou a pensar em como era difícil trabalhar a Educação Física com qualidade e de forma coletiva na escola [...].

(Narrativa escrita).

PM - a minha dúvida: [...] não sei se nós vamos nos referir às pesquisas de Mestrado e Doutorado, dos dois processos [...].

$\mathrm{PE}$ - eu acho relevante as duas [...] a diferenciação das duas, totalmente [...]. (Diálogos da narrativa oral - 09/01/2012).

A partir deste diálogo definem-se as duas pesquisas como referências e, tanto o PP como o PE evidenciam, a partir do questionamento da PM, que houve diferenciação no modo de fazer pesquisa no Mestrado e no Doutorado. No primeiro, o envolvimento das escolas e dos professores foi limitado e, por isso, a experiência de pesquisar e os conhecimentos advindos desta investigação foram mais significativos para o pesquisador do que para os colaboradores.

A pesquisa de Doutorado, realizada através de uma metodologia participativa, envolvendo os professores da escola e estagiários de um curso de Licenciatura em Educação Física, promoveu alterações visíveis no ambiente escolar. Ao discutirmos sobre a Educação Física na escola antes, e depois da referida pesquisa, o PE afirma que:

PE - [...] Eu acho que dessa forma talvez eu tenha desenvolvido mais e olhado para a questão oculta, para a questão do conteúdo oculto, mais após a pesquisa do que antes [...].

(Fragmento da narrativa oral - 09/01/2012).

As palavras do PE nos remetem às ideias de Giroux (1997), para quem a transmissão dos códigos morais e a aprendizagem de atitudes, para conformar as crianças e os jovens aos 'ideais' predominantes na sociedade, são, geralmente, desenvolvidas indiretamente por via do 'currículo oculto'. Segundo o autor, o ‘currículo oculto' é caracterizado por: 
[...] aquelas mensagens e valores que são transmitidos aos estudantes silenciosamente através da seleção de formas específicas de conhecimento, do uso de relações específicas em sala de aula, e das características definidoras da estrutura organizacional escolar (GIROUX , 1997, p. 36)

Ou seja, são as práticas e as rotinas do cotidiano que estabelecem um processo de naturalização dos valores levando o aluno à aceitação do mundo como ele é, sem discutir as verdades que lhe são impostas, sem que ele mesmo dê-se conta, tornando-se assim um sujeito acrítico.

Ao confessar ter ampliado ou aprofundado sua percepção quando passa a ver o conteúdo oculto, expressão mencionada acima, o PE permite compreender que a partir do processo do qual tomou parte, seu olhar de educador passou a ver para além do conteúdo em si, vislumbrando novos alcances e possibilidades na prática docente que se concretiza mediante a conjugação de atributos pessoais e profissionais. Do mesmo modo, ao relembrar algumas situações vivenciadas, esse professor reflete sobre mudanças ocorridas como pessoa e como profissional. Enfim, como ser inteiro que constitui o ser professor. Comenta que mudou de uma prática mais tecnicista para uma postura mais humanizada:

PE: Sim, era mais tecnicista. Muito mais parte física e jogo, o desporto. Continua sendo um pouco isto, mas essa questão social está muito mais presente hoje em dia. A questão de inclusão [...] A aproximação com a pessoa, a aproximação com o ser humano [...]

(fragmento da narrativa oral - 09/01/2012)

A partir da participação na pesquisa de Doutorado parece ter havido alterações significativas na visão do professor sobre a Educação Física, no sentido de vê-la de maneira mais coletiva. O PE busca integrar mais os colegas utilizando conteúdos menos esportivizados, dando maior intencionalidade para as aulas livres e tendo como referência o Projeto Político-Pedagógico da escola. Além disso, a procura de diálogo com os alunos se tornou frequente e ele inclusive sugeriu que se fizesse novamente uma pesquisa com os estudantes que tratasse da função da Educação, da Escola e da Educação Física, como ocorreu em 2006. Para ele:

PE: Claro que a gente é diferente. A gente muda, amadurece e enxerga outras coisas. A gente ouve mais. Aprende a ouvir mais o aluno, a dialogar mais. Aprende a aprender com o aluno, com estagiários, com os que têm menos experiência, com os que têm mais experiência [...]

PE: Mas eu como pessoa, com estas características de comunicação, de simplicidade em agir.... porque me disseram muitas vezes que eu tenho que estar acima dos meus alunos. Ok, eu fiz uma faculdade, né? Eu estou ali, com um cargo de professor não de aluno. Tudo bem. Isso é óbvio. Agora eu não preciso impor sempre com um tom e com uma posição muito superior. $\mathrm{Eu}$ posso dialogar, eu posso fazer com que eles entendam que a gente coordena $[\ldots]$ 
(fragmentos da narrativa oral - 9/01/2012)

As manifestações do professor revelam comprometimento com o ato educativo, com o exercício humanizado da docência evidenciando sensibilidade para perceber que é fundamental ser autoridade sem ser autoritário. Ao valorizar o processo de pesquisa admite também que a experiência vivida em ser professor, com o passar dos anos, vai transformando o sentido da docência na escola. No seu caso evidencia a procura de uma pedagogia mais humanizada, relacionada com o diálogo e com a reflexão.

PE:[...] Ninguém gosta de ser humilhado, de ser tratado com menosprezo. [...] Não vejo que se educa dessa forma. Mas isso é uma característica minha. [...] Porque como eu evoluí como ser humano para ser um cara mais paciencioso, mais calmo no tratar. Eu era mais faca na bota antes ${ }^{52}$. Mas isso é um amadurecimento. Vai ficando mais velho e vai ficando mais acessível.

(diálogo da narrativa oral - 09/01/2012)

Por outro lado ele se sente impulsionado pelo processo de pesquisa que participou estabelecendo relação da sua prática pedagógica com os estudos nos quais se envolveu.

PE: Com certeza eu desenvolvi muito isso antes e depois da pesquisa [...] Depois da pesquisa, é obvio. [...] Mas óbvio, inevitável porque a gente teve um trabalho, uma relação forte de discussão, de um pouco mais de aprofundamento, de embasamento em algumas coisas [...] E a gente chega claramente à conclusão de que essa é a forma de aprender e de construir. É dialogando!

(fragmentos da narrativa oral - 09/01/2012)

PE: Também tem a ver com as pesquisas. [...] pensando a respeito disso, na minha caminhada, eu penso que pode ser uma forma de valorizar esta questão de vivência, de questão pessoal em detrimento de uma falta de formação continuada.

(fragmentos da narrativa oral - 06/03/2012)

Interpretamos o momento de flexibilização pelo qual passa o professor como uma fusão de dois elementos básicos: a sua formação pessoal e a sua vivência na pesquisa. Este fato nos aproxima do pensamento de Huberman (1992) e de Nóvoa (1995) quando tratam das fases que compõem a carreira de professor. Para eles, com o passar do tempo e o distanciamento de uma formação continuada, o professor se utiliza de mediações possíveis dentro da escola, onde as reflexões sobre o contexto possibilitam avanços, paradas e retrocessos. Nessa perspectiva, para o professor:

52 Termo utilizado para representar uma posição menos flexível. 
PE: [...] tu tens muito mais o domínio da turma, tu aprende a enxergar mais o teu aluno, a entender as reações. Ao longo dos anos a gente vê as mesmas coisas. Então começa a lidar de outra forma. Começa a entender várias características que se repetem.

(fragmentos da narrativa oral - 06/03/2012)

Podemos inferir, então, que a partir de estudos que envolvem as escolas e os professores pode haver alterações significativas na formação continuada e nas práticas pedagógicas. Porém, duas ressalvas são necessárias: 1) as investigações que promovem um envolvimento maior das instituições de ensino e dos docentes no processo de pesquisa têm maiores possibilidades de transformações, pois exigem aprofundamento e geram uma formação em serviço, essencial para compreender e avaliar o projeto disciplinar e de escola; 2) a experiência docente continua sendo um aspecto motivador com relação às transformações e mudanças essenciais à escola.

Aspectos administrativos e da estrutura física e material

O tempo da história e o tempo do discurso (CHATMAN, 1988 apud CONNELLY e CLANDININ, 1995), na fala do PE e do PP se revelaram distintos enquanto eventos vividos e eventos contados, evidenciando, como destacam os autores, que a narrativa pode ser guiada, não por uma ordem cronológica, mas por um sentido de totalidade em que o detalhe e o todo conformam a globalidade do processo.

Nesse sentido, o PE começou sua narrativa voltando no tempo, mas nem sempre a cronologia guiou seus passos. Suas lembranças o levaram para a chegada na escola e suas impressões sobre a estrutura da mesma para a prática da Educação Física, em comparação com a escola anterior. Para ele a estrutura desta se apresentava melhor do que a da outra, o que, supostamente, indicaria também melhores perspectivas de trabalho.

PE: Encontrei nesta escola condições bem melhores de desenvolver um trabalho mais qualificado, pois a escola possui um espaço interno e outro externo com quadras de vôlei, futsal e handebol, porém com medidas reduzidas. [...] Ainda não havia estrutura para basquetebol o que mais tarde conseguimos com muito esforço.

(narrativa escrita)

Este mesmo espaço, para o PP, não se apresenta como algo que propicie boas alternativas de trabalho. Para ele existiam somente dois espaços específicos.

PP: A escola tinha somente dois espaços específicos para as atividades práticas: um pequeno auditório transformado em ginásio e uma quadra externa. Uma dificuldade sentida naquele período era de que, em determinadas manhãs, os três professores tinham aulas ao mesmo tempo o 
que criava um problema de divisão de espaço físico que se agravava em dias de chuva.

(narrativa escrita)

É possível observar que os dois professores citam as condições físicas da escola, entretanto cada um fala de sua ótica. O que para um pode parecer um bom espaço porque comparado com outra escola, em condições piores, oferece melhores perspectivas de trabalho, para outro são apenas "dois espaços específicos" que na realidade, como o próprio professor da escola retoma, em alguns momentos criava dificuldades. Historicamente muitos professores se veem obrigados a melhorar as condições materiais e de infraestrutura para atender melhor os alunos. Com este professor não foi diferente, como observamos na fala abaixo:

PE: Eu lembro também que, uma das coisas que fizemos, foram as quadras de mini vôlei atrás das goleiras, para esse tipo de atividade. [...] A gente poderia ter um grande grupo dentro do salão fazendo outro tipo de atividade. [...] a gente conseguiu uma goleira móvel. Assim, poderia ter um futebol na rua, um handebol dentro do salão, as duas quadras de mini vôlei. Tinha uma participação maior dos alunos, ou até mesmo que tivesse um vôlei de grande grupo dentro do salão. Os menores que ainda não tinham tranquilidade de jogar na quadra começavam a jogar na rua.

(fragmentos da narrativa oral - 09/01/2012)

Há, na fala do professor, uma clara preocupação com a democratização do acesso às aulas, oportunizada pela criação de melhores estruturas que trariam também novas possibilidades para alunos menos habilidosos. Estes se sentiam constrangidos em participar de situações de jogo com colegas presumidamente mais habilidosos.

Ainda com relação aos espaços, o professor comenta:

PE: Mas, depois com a chegada de outra professora, essa utilização do espaço se tornou mais complicada. Mais um professor e a dificuldade em administrar esses espaços também mexeram com a dinâmica das aulas. É aí que começa aquela fase das socializações, assim denominada pelo PP na época do projeto de Doutorado, porque a gente chamava de aulas livres, pois não havia uma orientação pedagógica. Era uma aula de jogo livre.

(fragmento da narrativa oral - 09/01/2012)

Importante destacar a menção feita pelo professor à questão das aulas livres, expressão muito utilizada para as situações em que os alunos praticam esportes com pouca ou nenhuma intervenção do professor e também onde parece não haver uma intencionalidade pedagógica. Estas aulas passam a ter outra orientação e propósito a partir da presença do PP.

Ao chegar na escola para fazer a coleta de informações para sua dissertação de mestrado, em 1999, as impressões do PP indicaram a dificuldade de troca de espaços entre os professores da disciplina. 
PP: Como as atividades eram regidas diferentemente pelos professores, pouco se via de articulação coletiva para a superação de problemas no sentido de atender as turmas através de combinações. As aulas eram individualizadas e planejadas de acordo com a vontade de cada professor. Sendo assim, era difícil um diálogo no sentido de estabelecer ações coletivas para a utilização dos espaços já precarizados.

(narrativa escrita)

Ainda sobre questões de espaço, outro problema destacado pelo PE se relaciona à mudança na organização dos horários da Educação Física em anos anteriores. Tal fato foi decorrente de um processo de desmobilização e falta de diálogo dos professores dessa disciplina diante da reclamação dos outros docentes sobre o excesso de ruído no pátio. Assim a Educação Física passou a ser concentrada em apenas três dias na semana fazendo com que todos os professores tivessem que dividir entre si apenas dois espaços físicos. Na sua fala:

PE: Eu não sei se eu cheguei a comentar isso [...] mas é importante a gente falar o motivo que a Educação Física foi colocada toda junta, ou seja, os horários dos três professores o mais junto possível. Houve um movimento dos professores de sala de aula para que isso acontecesse em função do barulho, diminuindo assim os dias de aula no pátio da escola [...] Com a saída de uma professora e a vinda de outra, tivemos que mexer novamente nos horários, voltando a ter aulas todos os dias da semana e uma melhor distribuição dos espaços [...]

(fragmento da narrativa oral - 09/01/2012)

Notamos, entretanto, que durante o desenvolvimento da pesquisa de Doutorado uma organização mais racional do espaço físico e dos horários para a Educação Física foi utilizada, além da colocação de uma tela para separar os alunos em aula dos outros. Estes fatos evidenciam uma mudança na forma de ver a Educação Física pelos professores e pela direção da escola. Neste sentido, a pesquisa incentivou uma nova organização estrutural da Educação Física que se mantém até hoje.

Conforme destacam PE e PP, a partir das pesquisas desenvolvidas, mudanças significativas puderam ser observadas na escola. Além da problemática do espaço outras situações como falta de professores, provas de outras disciplinas, alunos pulando muros, mesmo se constituindo problemas externos às aulas, interferiam diretamente nas mesmas, como comenta o PP:

PP: [...] turmas que não tinham aulas porque os professores faltaram ou que faziam provas eram encaminhadas à Educação Física ou ao pátio onde aconteciam as aulas. Estes alunos, juntamente com aqueles que gazeavam aula tentavam constantemente se infiltrar nas atividades dos professores criando novos problemas para os docentes. [...]

(narrativa escrita) 
Daí a lembrança do cercamento do pátio como uma medida tomada pela escola por ocasião do trabalho de investigação, mencionada pelo PP:

PP: A nosso pedido a escola cercou o pátio destinado à Educação Física, estabeleceu um período de reunião semanal e deixou de colocar turmas sem professores para as atividades no pátio. Por isso entendemos que o projeto já estabeleceu certa ordem na escola.

(narrativa escrita)

O PE concorda que tal medida, mesmo não tendo resolvido integralmente o problema, implicou na sua ocorrência em menores proporções.

PE: Eu tinha esquecido aquela parte que a escola foi cercada [...] ainda tinha esse agravante porque se eles não entravam pelo portão, faziam a volta e entravam pelo salão. Mas em muito menor número.

(fragmento da narrativa oral - 9/1/2012)

Apesar da direção atual não ser mais aquela que acompanhou o estudo de Doutorado existe uma sensibilização sobre as demandas da Educação Física, como a aquisição de material e a reorganização dos horários em função das necessidades dos professores.

Aspectos didático-pedagógicos

Para discutir aspectos didático-pedagógicos que contracenam com outros elementos presentes neste trabalho nos valemos das reflexões de Marques (2006) sobre a Pedagogia, uma vez que para esta, segundo o autor, as relações entre teoria e prática não são apenas referências obrigatórias, mas fundantes e constitutivas da análise e da reflexão sobre o processo educativo.

Em sua especificidade de ciência referida a uma prática determinada, a Pedagogia não é apenas conhecimento $d a$ educação feita ou para a educação a fazer-se, mas conhecimento que se constrói audazmente ao fazer-se a educação e como diretriz, sempre provisória, para as decisões exigidas a cada passo e momento e no interior do próprio processo de educação. (MARQUES, 2006, p. 97).

Nessa perspectiva, retomando os movimentos ocorridos na escola por conta das dinâmicas implementadas já na pesquisa de Doutorado, o PP resgata o processo lá realizado:

PP: No intuito de dar um tom coletivo nos propusemos a estudar e construir um projeto pedagógico junto com os estagiários no primeiro semestre de 2006, que foi efetivado. Porém, nenhuma alteração significativa ocorreria na escola sem a inclusão dos estudantes neste processo, por isso fizemos uma pesquisa de opinião sobre a função da escola e da Educação Física na vida deles.

(narrativa escrita) 
Na manifestação acima o PP expressa sua intenção de constituir, no âmbito desta escola, uma coesão, uma articulação entre professores de Educação Física e estagiários da disciplina para a construção de um projeto pedagógico. Entretanto, ressalta que sem a inclusão dos alunos, parte integrante e constituinte do processo, poucos avanços ocorreriam.

Marques (2006), ao refletir sobre a importância do projeto pedagógico, destaca que a ação educativa como prática social orienta-se pela intencionalidade declarada e não pelo ativismo espontaneísta. $\mathrm{O}$ direcionamento explícito e consciente é o que caracteriza o projeto pedagógico. Nesse sentido afirma:

A substituição das interações espontâneas por interações pedagógicas faz com que as práticas concretas da educação escolar sejam, de fato e sempre, organizadas e conduzidas, inseparáveis, portanto de um projeto pedagógico. Desta maneira, toda a dinâmica da ação educativa e, da ação educativa institucionalizada, deriva do projeto ou proposta que a anima e informa, impulsiona, organiza e conduz (MARQUES, 2006, p. 146).

Na continuidade de sua fala o PP comenta as dificuldades percebidas a partir da resistência apresentada pelos alunos ao longo das aulas, mesmo com a existência do projeto.

PP: Após a construção do projeto pedagógico fomos a campo exercitar nossa prática e notamos que poucos avanços tivemos, porque os alunos continuavam resistindo às atividades orientadas. $\mathrm{O}$ gasto de forças para que professores e estagiários convencessem as turmas para realizar as atividades era enorme.

(narrativa escrita)

Tardif (2002) nos ajuda a entender tal fato ao refletir sobre o objeto de trabalho do professor. Entende que este não age pensando apenas em objetivos, mas também sobre seres humanos, indivíduos cujas particularidades estão circunscritas a um contexto social. Para este autor:

Embora ensinem a grupos, os professores não podem deixar de levar em conta as diferenças individuais, pois são os indivíduos que aprendem e não os grupos. Esse componente individual significa que as situações de trabalho não levam à solução de problemas gerais, universais, globais, mas se referem a situações muitas vezes complexas, marcadas pela instabilidade, pela unicidade, pela particularidade dos alunos, que são obstáculos inerentes a toda a generalização, às receitas, e às técnicas definidas de forma definitiva. (TARDIF, 2002, p. 129)

O trabalho relatado traz também aspectos significativos que apontam avanços ocorridos na relação com os estagiários a partir do diálogo estabelecido com os alunos. O comentário a seguir indica que os estagiários passaram a ser respeitados como autoridades docentes e que os conteúdos previamente propostos também passaram a ser considerados.

PP: Porém, alguns indicativos foram positivos como o estabelecimento de um diálogo constante com os alunos, entre os professores, entre os estagiários e o supervisor/pesquisador. [...] Pedagogicamente notou-se que este diálogo introduziu mais fortemente a figura do estagiário na escola que 
não precisou constantemente do auxílio do professor nas questões relativas à aula. Outro fator positivo foi a utilização de conteúdos propostos especificamente dentro do projeto pedagógico, desqualificando as metodologias mais espontaneístas onde o professor abre uma caixa de surpresas na frente dos alunos.

(narrativa escrita)

Na visão de Freire (1983) a ação dialógica mediadora e com níveis de hierarquia mais equilibrados podem levar os sujeitos envolvidos a ações conjuntas que os façam superar determinados problemas. Na escola, dialogar com estudantes pode levar a uma compreensão maior sobre o que pensam do mundo e da escolarização, por exemplo. A partir daí a seleção de conteúdos e de procedimentos de ensino pode ser alterada numa perspectiva de incluir as necessidades dos estudantes nas disciplinas escolares.

Nesse sentido o PE também destaca os aspectos que evidenciam avanços na educação física através das trocas entre os segmentos envolvidos - alunos, professores e direção - confirmando o que nos traz Paulo Freire quando valoriza o diálogo como elemento de mediação.

PE: A Educação Física era bem mais desorganizada, falando no geral, falando de estrutura de aula, de divisão de espaço. Era bem mais desorganizada do que está hoje. Todo esse processo que a gente conversou de direcionamento de conteúdo, de discussão com os alunos e com a direção, toda essa construção, não tem como não mudar [...] foi um processo de mudança.

(fragmento da narrativa oral - 09/01/2012)

Parece, entretanto, que a conscientização dos alunos sobre a importância da Educação Física ainda tem um caminho a ser percorrido. O PE reconhece que os alunos têm que ser preparados quando iniciam a Educação Física nas séries finais do Ensino Fundamental.

A proposta de pesquisa participativa que norteou o processo de Doutorado se constituiu, então, como uma grata aprendizagem ao pesquisador e ao professor. Esta forma de pesquisar numa relação mais equilibrada entre os sujeitos mostrou a relevância do diálogo na escola. Estudar os textos, debater as práticas, refletir sobre as ações, auto-avaliar constantemente o processo de aulas e dialogar com alunos e direção fez com que ambos compreendessem melhor a educação escolar e a Educação Física. Fez com que avançassem de uma consciência ingênua sobre a escola para uma consciência mais reflexiva ou crítica.

Para Freire (2003, p. 69) é a transitividade crítica que leva o ser humano a uma "educação dialogal e ativa, voltada para a responsabilidade social e política". Entretanto, o autor chama a atenção para o entendimento de que a criticidade é se posicionar coerentemente no mundo e a conscientização é o desenvolvimento consciente de tomada de decisão.

\section{Conclusão}

Ao utilizarmos a narrativa como processo metodológico, observamos como podem ser ricas de representações e de significados as falas e as escritas dos envolvidos. Vamos ao encontro da ideia 
de Abrahão (2005) que afirma que uma narrativa trata de ressignificar uma experiência de vida a partir de uma relação de cumplicidade entre sujeito e pesquisador. No nosso caso específico, a relação que se estabeleceu foi pautada pelo diálogo onde todos fomos participantes e construtores deste texto a partir dos nossos olhares que embora distintos se conjugaram em torno do mesmo objeto: a Educação Física numa Escola Pública.

Ao nos encaminharmos para um fechamento que não se constitui num produto conclusivo, mas num processo que, guardadas as suas provisoriedades, encerra-se por uma arbitrariedade espaço-temporal, percebemos que a pesquisa de Doutorado marcou bem mais a escola e as pessoas envolvidas do que nos pareceu num primeiro momento. Fica-nos a impressão que o processo participativo fez com que professores e direção se voltassem a um objetivo comum - dar melhor qualidade à Educação Física escolar - e, com isso, articulassem ações conjuntas que poderiam ser levadas adiante após o término do estudo.

Alguns aspectos traduzem os movimentos que podem representar as mudanças ocorridas na escola, com implicações na disciplina de Educação Física: um projeto pedagógico que continua sendo referência após cinco anos do estudo; a estrutura das aulas se mantendo com maior intencionalidade; a divisão de turmas e de horários mantendo uma coerência em prol do desenvolvimento de atividades viáveis para a Educação Física; e, talvez o mais relevante: um processo dialógico de resolução de problemas, principalmente com os alunos passou a ser referência no tratar pedagógico cotidiano.

\title{
REFLECTING ABOUT SCHOOL PHYSICAL EDUCATION WITH NARRATIVES
}

\begin{abstract}
This article resulted from a study group proposal for conducting a narrative exercise with its faculty researchers and their partners, who are school teachers. Its goal was to understand the implications of research conducted in participating educational institutions. The methodology used was the oral and written narratives, involving three teachers: two researchers from the group and a Physical Education teacher from a public school. The study has shown that the conducted research promoted changes in the trajectory of the teachers, administrative organization, physical structure, school supplies, as well as pedagogical and didactic aspects of teachers' work.
\end{abstract}

Keywords: School Physical Education. Narratives. Dialogue.

\section{REFLEXIONES SOBRE EDUCACIÓN FÍSICA ESCOLAR CON NARRATIVAS}

\section{Resumen}

Este artículo resultó de la propuesta de un grupo de estudio, para llevar a cabo un ejercicio con narraciones que involucran docentes e investigadores del propio grupo y sus interlocutores, los profesores de escuelas; tuvo como objetivo comprender las implicaciones de la investigación llevada a cabo en las instituciones educativas investigadas. La metodología utilizada fue la narrativa oral y escrita, con la participación de tres profesores, dos investigadores del grupo y un profesor de Educación Física de una escuela estatal. El estudio mostró que la investigación desarrollada hapromovido cambios en la trayectoria de los profesores, en la organización administrativa, en la 
estructura física y en el material de la escuela, así como en los aspectos didácticos-pedagógicos del trabajo docente.

Palabras-clave: Educación FísicaEscolar. Narrativas. Diálogos.

\section{Referências}

ABRAHÃO, M. H. M. B. As Narrativas de Si Ressignificadas pelo Emprego do Método Autobiográfico. In: SOUZA, E. C. de; ABRAHÃO, M. H. M. B. (org.). Tempos, Narrativas e Ficções: a invenção de si. Porto Alegre: EDIPUCRS, 2006. p. 149-169.

CONNELLY, F. Michael; CLANDININ, D. J. Relatos de Experiencia e Investigación Narrativa. In: LAROSSA, Jorge (org.). Dejame que te Cuente: ensayos sobre narrativa y educación. Barcelona: Editora Laertes, 1995. p. 11-59.

CUNHA, M. I. da. As narrativas como explicitadoras e como produtoras de conhecimento. In: CUNHA, M. I. da. O Professor Universitário na Transição de Paradigmas. Araraquara: JM editora, 1998. 118 p. 37-46.

FREIRE, P. Pedagogia do Oprimido. 12. ed. Rio de Janeiro: Paz e Terra, 1983. 220 p.

FREIRE, P. Educação como Prática da Liberdade. 27. ed. Rio de Janeiro: Paz e Terra, 2003. 158 p.

GIROUX, H. A. Os Professores Como Intelectuais: rumo a uma pedagogia crítica da aprendizagem. Porto Alegre: Artes Médicas, 1997. 270 p.

HUBERMAN, M. O ciclo de vida profissional dos professores. In: Nóvoa, António. Vidas de professores. Porto: Porto, Porto, 1992. p. 31-61.

ISAIA, Silvia Maria de Aguiar. Glossário. In: MOROSINI, Marília Costa (org.). Enciclopédia de Pedagogia Universitária. Porto Alegre: Fapergs/Ries. 2003. p. 281-424.

MARQUES, M. O. Pedagogia: a ciência do educador. Ijuí/Brasília: UNIJUÍ/INEP, 2006. p. 188.

NÓVOA, A. O Passado e o Presente dos Professores. Em NÓVOA, A. (org.). Profissão Professor. $2^{\mathrm{a}}$ Ed. Porto: Porto, 1995. p. 13 a 34.

TARDIF, M. Saberes Docentes e Formação Profissional. Petrópolis: Rio de Janeiro: Vozes, 2002. p. 325. 
Recebido em: 30/04/2014

Revisado em: 04/04/2015

Aprovado em: 11/04/2015

Endereço para correspondência:

ALEXANDRE SCHERER

scherer@via-rs.net

Instituto Porto Alegre, Curso de Educação Física, Professor de Graduação e Pós Graduação.

Rua Coronel Joaquim Pedro Salgado, 80

Rio Branco

90420060 - Porto Alegre, RS - Brasil 